\title{
METÁFORAS DA MORTE ENTRE PÓS-PUNKS: PASSOS PARA UMA TEORIA DA AÇÃO DESDE BATESON ${ }^{1}$
}

\author{
Carusa Gabriela Biliatto ${ }^{2}$
}

\begin{abstract}
RESUMO
Neste texto apresento como é elaborada a relação entre a reflexividade sobre juventudes, desigualdade e exclusão e a sistematicidade do imaginário sonoro etnografado. 0 artigo tem por um objetivo mostrar o vínculo entre fazeres musicais e reflexividade no II Festival Woodgothic. A hipótese de trabalho é de que tal vínculo consiste em uma relação de homologia da qual resulta a modalidade de reflexividade que denomino como "reflexividade blues punk". 0 referencial teórico da análise parte da abordagem de Gregory Bateson, sobre o ruído e os códigos de comunicação em homologia a padrões de ação; e as formulações de Margaret Archer, sobre reflexividade e conversações internas. Conclui-se que 0 vínculo entre arte e experiência indica a presença do modo blues punk de reflexividade situado nas várias camadas do cotidiano do agente. 0 modo blues punk atua como operador prático das categorias de apreciação que deliberam os posicionamentos do agir, portanto, produtos da reflexividade inscrita nas malhas do cotidiano.
\end{abstract}

Palavras-chave: Teoria da ação. Juventudes. Reflexividade. Metáforas da morte. Biopoder.

\footnotetext{
${ }^{1}$ Uma primeira versão deste artigo foi apresentada no II Encontro Internacional Sobre Imaginários Sonoros e I Encontro de Música e Tecnologia, nos dias 4 a 7 de novembro de 2013, na Universidade Federal do Paraná, Curitiba, Brasil, na Mesa-"Sonoridades e identidades".

${ }^{2}$ Doutoranda em Ciências Sociais pela Pontifícia Universidade Católica de São Paulo e Professora substituta no Departamento de Ciências Sociais da Universidade Federal de Santa Maria, Brasil. carusagabriela@yahoo.com.br
} 


\title{
METAPHORS FOR DEATH AMONG POST-PUNKS: STEPS TO A THEORY OF ACTION SINCE BATESON
}

\begin{abstract}
The text shows the way in which the relationship between reflexivity on youths, inequality and exclusion, on the one hand, and the systematicity of the ethnographed sonorous imaginary, on the other, is established. The article purports to demonstrate the link between music-making and reflexivity in the II Woodgothic Festival. The working hypothesis is that such link constitutes a relationship of homology from which a mode of reflexivity I call blues punk emerges. The theoretical framework is based on Gregory Bateson's approach on noise and on the homology between communication codes and patterns of action, and Margaret Archer's formulations on reflexivity and internal conversations. My claim is that the bond between art and experience indicates the presence of the blues punk reflexivity mode, located at the various layers of the agent's daily life. The blues punk mode acts as a practical operator of the appreciation categories that deliberate on the positionings of acting, thus products of the reflexivity inscribed in the everyday textures.
\end{abstract}

Keywords: Theory of action; Youths; Reflexivity; Metaphors for death; Biopower.

Mito codificado em sons no lugar de palavras, a obra musical oferece uma grade de deciframento, uma matriz de relações que filtra e organiza a experiência vivida, a substitui e propicia a benfazeja ilusão de que as contradições podem ser superadas e as dificuldades resolvidas.

Lévi-Strauss, 0 bomem $\mathrm{nu}$

Essa questão da localização da informação endemoninhou a teoria da comunicação (...). Tudo o que não é informação, nem redundância, nem forma e nem restrição - é ruído, que é a única fonte possível de novos padrões.

Bateson, Steps to an ecology of mind

\section{INTRODUÇÃO}

E ste artigo faz parte de uma pesquisa etnográfica iniciada em maio de 2005, acerca da negatividade como categoria da experiência cotidiana. Insere-se, também, no desenvolvimento da atual pesquisa de doutorado situada na interface entre Teoria Antropológica e Filosofia das Ciências Sociais, que focaliza especificamente a relação entre as contribuições de Gregory Bateson para uma teoria da ação e a negatividade como categoria da experiência cotidiana, propondo-se, em paralelo, um diálogo com a obra Razões Práticas, de Pierre Bourdieu, na explicitação das categorias específicas de 
uma "razão plástica". Para este artigo, retorno à interpretação de alguns dados da pesquisa realizada no âmbito do mestrado, a morte e seu duplo - micropolítica das emoções no II Festival Woodgothic (BILIATTO, 2012). Mediarei a interpretação por um objetivo preciso, qual seja, o de analisar como é elaborado, no contexto etnográfico indicado a seguir, o vínculo entre fazeres musicais e reflexividade. Mais especificamente, analiso como é elaborada a relação entre a reflexividade sobre juventudes, desigualdade e exclusão, a partir dos fazeres musicais no II Festival Woodgothic.

No caminho conceitual, dois autores inspiram esta análise: a socióloga Margaret Archer (por sua formulação sobre reflexividade e conversações internas) e o antropólogo Gregory Bateson (por sua abordagem sobre o ruído e os códigos de comunicação em homologia a padrões de ação), conforme será explicitado à frente.

A hipótese de trabalho é a de que a relação entre reflexividade e fazeres musicais no II Festival Woodgothic consiste em uma relação de homologia da qual resulta uma modalidade de reflexividade que denominarei, provisoriamente, como "reflexividade blues punk". Nesse quadro, uma das conclusões que proponho é a de que o vínculo etnografado entre arte e experiência indica a presença de um uso $0^{3}$ do modo blues punk de reflexividade situado, sistematicamente, na posição de ponto de ver, por consequência, através das várias camadas do cotidiano do agente. Nessa intersecção, o referido modo atua como operador prático das categorias de classificação e de apreciação que, pelo veículo das conversações internas, deliberam-sempre em relação à sistematicidade do modo blues punk - os posicionamentos do agir, portanto, produtos da reflexividade inscrita nas malhas da finitude carnaz e molecular do cotidiano.

Antes de prosseguir, gostaria de referir algumas palavras de localização quanto ao trecho de Lévi-Strauss (2011) em epígrafe. A passagem pertence ao capítulo "Finale" de 0 bomem $n u$, último volume das Mitológicas. Nesse capítulo, uma das seções é dedicada à análise da posição da obra musical nas sociedades ocidentais ${ }^{4}$ contemporâneas em relação de homologia à posição do mito nas sociedades

\footnotetext{
${ }^{3}$ Por usos “trata-se precisamente de reconhecer 'ações' (...) que são a sua formalidade e sua inventividade próprias e que organizam em surdina o trabalho de formigas do consumo" (CERTEAU 2009, pp. 87-88). 0 autor se refere a consumo tanto de objetos das indústrias quanto consumo de valores, regras, normatividades.

${ }^{4}$ Adicionalmente, assinalo a autorreferência temporal da expressão e, ao mesmo tempo, a sua condição de atualização permanente, portanto, precariamente definível em relação ao que se entende por "Ocidente". Franco Júnior propõe uma definição meramente operacional, mas que, todavia, demarca os contornos da produção social do sentido da palavra "ocidente": "na época carolíngia [séculos VIII-IX], era sinônimo de Império e Europa. Nos séculos XI-XIII, em virtude do contato mais próximo com bizantinos e muçulmanos e o consequente despertar de uma consciência ocidental, designa a área de língua e cristianismo latinos. Por volta de 1500 ganhou também sentido político, oposto ao Oriente de déspotas de poder ilimitado e arbitrário.” (FRANCO JÚNIOR, 2006, p. 184).
} 
examinadas pelo autor nos quatro volumes das Mitológicas. Essa proposição está apoiada na interpretação de que, para nossa contemporaneidade, desde uma visão estrutural, nos termos do autor, a posição do pensamento mítico foi evacuada e ocupada pela música. A partir de essa localização da posição da obra musical em nossos dias, Lévi-Strauss sintetiza a indicada proposição nas palavras da epígrafe.

Em relação ao contexto etnografado, que apresentarei a seguir, interpreto a síntese citada de Lévi-Strauss articulada à noção de reflexividade de Margaret Archer (2003), pensada por esta autora nos seguintes termos:

Todo mundo é um ser reflexivo. Isso significa que deliberar sobre as circunstâncias em relação a nós mesmos e, à luz dessas deliberações, nós determinamos nossos próprios cursos pessoais de ação na sociedade. No entanto, nem todos nós exercemos a nossa reflexividade da mesma forma. Todos têm um domínio de privacidade mental, a partir do qual subjetivamente examina e avalia as suas circunstâncias externas, dentro do qual saboreia suas satisfações ou nutri seus descontentamentos, e através dos qual monitora suas ações futuras. 0 veículo de tudo isto é a conversação interna. Contudo, a natureza de nossas conversações internas está longe de ser idêntica e essas diferenças excedem idiossincrasias pessoais. Os diferentes tipos de conversação interna são importantes porque eles estão intimamente relacionados com as diferentes formas de deliberações e, em última análise, o tipo de modus vivendi que um agente procura estabelecer no mundo. (ARCHER, 2003, p. 167. Tradução minha).

Considero que a mencionada articulação, em primeiro lugar, permite-nos ajustar 0 grau de abstração em direção a uma aproximação em relação à realidade etnografada. Portanto, a relação de mediação entre teoria e empiria almejada pelo trabalho e escrita etnográficos, nesse caso, encontram o ajuste do grau de abstração, destinado ao referido exercício de mediação, no indicado modo de uso da noção de reflexividade e de conversação interna. ${ }^{5}$ Por sua vez, a passagem de Lévi-Strauss nos sinaliza a profundidade, como veremos à frente, do fim último com o qual se debate a "reflexividade blues punk" aqui analisada sob o vínculo entre música e experiência. Na medida em que o autor sintetiza que na música em nossas sociedades atuais, homologamente ao mito alhures e algures, encontramos um invariante operador do

\footnotetext{
${ }^{5}$ A relação de mediação entre teoria e empiria sistematiza o movimento que vai desde a teoria para inteligibilidade da realidade etnografada e, necessariamente, a inverso, vem da realidade etnografada para a (re)visão da epistemologia da teoria. Precisamente, pois, este é o exercício de mediação desafiador do trabalho antropológico quanto à sua tarefa de emprestar inteligibilidade analítica às direções da realidade examinadas.
} 
pensamento que "propicia a benfazeja ilusão de que as contradições podem ser superadas e as dificuldades resolvidas" (LÉVI-STRAUSS, 2011, p. 636).

\section{O Festival WoOdgothic}

É preciso deixar claro que "gótico" foi o nome que os "pós-punks" ganharam no Brasil, e é indicativo do nome do Festival Woodgothic. Este é um evento musical, realizado no Centro de Eventos da cidade de São Thomé das Letras, estado de Minas Gerais, Brasil. Conforme dados do Instituto Brasileiro de Geografia e Estatística - IBGE, em 2007 o município contava 6.617 habitantes, dentre os quais, 3.146 viviam na zona rural e 3.471 na zona urbana. Dados do Instituto de Pesquisa Econômica Aplicada IPEA informam que, em 2008 eram 6.880 habitantes no município. Portanto, pode-se dizer que a cidade configura uma miniatura de urbanidade e, apesar disso, apresenta um forte caráter cosmopolita-discussão que foge aos objetivos deste artigo.

A pesquisa de mestrado teve por tema as metáforas ${ }^{6}$ da morte no II Festival Woodgothic. Mais particularmente, trata-se de um estudo sobre a modalidade de elaboração de representações da morte nas produções artísticas que compõem o referido festival. Por ser um evento feito por e para pós-bunks, os organizadores do evento advogam a categoria underground como caracterizador do caráter do Festival e, ademais, apresentam-se pela descrição de núcleo de resistência underground. Para desenvolver a pesquisa, trabalhei, sobretudo, com os integrantes das bandas, com os DJs e os organizadores do festival, mediante entrevistas em profundidade e observação participante. Além disso, trabalhei com alguns tipos de dados coletados no ciberespaço, mediante a observação de atividades alocadas no sítio eletrônico oficial do evento e em duas redes sociais virtuais. Portanto, por estes caminhos procurei maneiras para compreender os percursos convergidos pelo II Festival Woodgothic.

\footnotetext{
${ }^{6}$ Mary Catherine Bateson, filha de Gregory Bateson, que terminou o manuscrito sobre o qual ele trabalhava no momento de sua morte, explica o uso do vocábulo "metáfora" feito pelo autor: "estrictamente es un recurso literário por el cual una descripción se extiende desde un objeto a otro con el cual aquél comparte ciertas características. A veces es cotejada con 'símil', figura en que la comparación es explícita, pero la metáfora, al hacer comparación explícita, propone cierto grado de identidad. Para Gregory Bateson la metáfora abarca todos los processos de conocimiento y comunicación que dependen de afirmaciones o exhortaciones de similitud, incluso, la "homología", la "empatía" o la "abdución". (BATESON e BATESON 1994, p. 206). Para validar melhor a compreensão, acrescento que "homologia", segundo a definição de Bateson, entende-se por "semelhança formal entre dois organismos de modo que as relações entre determinadas partes de A sejam similares às relações entre as partes correspondentes de B. Tal semelhança formal é considerada como evidência de relações evolucionárias." (BATESON, 1986, p. 233). É importante referir que, para Bateson, organismo significa todo e qualquer sistema de relações portador da condição de responder à diferença. Para o conceito de diferença, ver Bateson, (1972, pp. 479495).
} 
A programação principal do Festival é formada por apresentação de bandas e DJs. A primeira edição ocorreu nos dias 2 e 3 de maio de 2008, na qual treze bandas e três DJs atuaram com um público de aproximadamente duzentas e cinquenta pessoas. A segunda edição ocorreu nos dias 3, 4 e 5 de junho de 2010, quando quinze bandas e sete DJs atuaram com um público de aproximadamente duzentas e cinquenta e sete pessoas. A segunda edição do evento juntou aos concertos a exposição de dois desenhistas, um cartunista e três distribuidoras de discos. Os participantes do evento são provenientes de várias localidades do Brasil, por isso, é considerado o principal evento pós-punk nacional. Em sua segunda edição, o Woodgothic contou também com a participação de quatro músicos internacionais, por isso, e apesar de sua dimensão incipiente, procedeu a estender-se para além das suas iniciais fronteiras, constituindo uma referência internacional de eventos pós-punks no Brasil.

Aprofundando trabalhos anteriores sobre a temática dos usos do significante morte nas culturas pós-punk, a pesquisa de mestrado se localizou no campo da antropologia das juventudes, sobretudo no segmento que se ocupa com questões relacionadas ao lazer e aos usos do significante morte. A abordagem foi orientada por uma literatura de antropologia das emoções na medida em que as representações da morte, então etnografadas, consistiam, propriamente, em representações de emoções referentes à morte. Nessa intersecção, trabalhei com um sistema de emoções que sintetizei como uma categoria da experiência cotidiana, cuja figura tipificadora é a metáfora da morte. Particularmente, o sofrimento como metáfora da morte, posto que os interlocutores tomam experiências de sofrimento como categoria da experiência cotidiana usada para compor seus fazeres musicais sempre em relação de quiasma com as determinações da desigualdade sobre seus projetos de vida. No caso deles, trata-se, sobretudo, de músicas do bunk rock e pós-punk rock?.

\section{PADRões de MENSAGENS HOMÓlogos A PADRÕES DE AÇÃO}

Para iniciar a interpretação, o Festival Woodgothic tem lugar em uma ruptura do cotidiano do lazer habitualmente frequentado pela cena pós-punk, circunscrito ao cotidiano metropolitano das respectivas cidades das quais são provenientes seus frequentadores. Por essa perspectiva, o Festival produz um alargamento da experiência ligada aos afetos que a mencionada "cena" reunida vivencia coletivamente durante os dias do evento, ocasionando, então, uma intensificação das ligações que conectam 0

\footnotetext{
${ }^{7}$ A relação de quiasma entre os fazeres musicais e as determinações das desigualdades sobre os projetos de vida foi também discutida por Abramo (1994) em seu trabalho pioneiro sobre os pós-punks no Brasil. Para atualização da discussão, especificamente, sobre a referida relação, ver: Ferreira (2010, 2008); Pais (2001); Feixa (1998); Freire Filho (2007); entre outros.
} 
"entre si" ${ }^{8}$ dos woodgóticos. 0 mencionado "entre si" pode ser melhor compreendido a partir da

(...) preocupação de dar vida aos territórios e às localidades, e assim de reterritorializar e de relocalizar o que a globalização tanto desterritorializou e deslocalizou. Só pode existir convivialismo na abertura aos outros, certamente, mas também em um entre si suficientemente sólido para que seja fonte de confiança e cordialidade (MANIFESTO CONVIVIALISTA, 2013, p. 79. Grifo meu)

Concentrarei aqui a atenção no vínculo entre música e reflexividade, intensificado na alocação do Festival em uma ruptura e em uma passagem em relação à relativa continuidade do cotidiano. Considero a noção de "passagem" a partir da formulação de Victor Turner, que a analisa como liminaridade. Â luz deste autor, vemos que o Festival contém

(...) os atributos da liminaridade, ou de personae (pessoas) liminares que são necessariamente ambíguos, uma vez que esta condiç̧ão e estas pessoas furtam-se ou escapam à rede de classificações que normalmente determinam a localização de estados e posições num espaço cultural. As entidades liminares não se situam aqui nem lá; estão no meio e entre as posições atribuídas e ordenadas pela lei, pelos costumes, convenções e cerimonial. Seus atributos ambíguos e indeterminados exprimem-se naquelas várias sociedades que ritualizam as transições sociais e culturais. (TURNER, 1974, p. 117)

Compreenderíamos, então, sobre este aspecto, que o Festival também pode ser lido inicialmente sob a forma da categoria "aventura", nos termos de Georg Simmel (1988, p. 17). A formalidade mais geral e indecomponível nos granulares tipos lógicos de significados do evento - inclusive da relação entre música e experiência - posicionase signatária à categoria "aventura", situada, segundo sugere Simmel, na posição de "ilha" em relação à relativa continuidade do cotidiano. Tal posição define-se pela relação que $x$ vivência trava com o todo de nossa vida sendo sintetizada pelo autor "como un cuerpo extraño en nuestra existência que, no obstante, está de algun modo vinculado con su centro. Lo exterior es, bien que a través de um vasto e insólito rodeo, una forma de lo interior" (SIMMEL, 1998, p. 18).

\footnotetext{
${ }^{8}$ A primeira versão do Manifesto Convivialista foi redigida por Alain Caillé, todavia, a versão final publicada é sem autoria individual, uma vez que, propriamente, trata-se de um esforço coletivo de proposições. Para consultar mais sobre o assunto, ver: Les convivialistes, disponível em $<\mathrm{http}$ //lesconvivialistes.fr/> e o Jornal du MAUSS (Mouvement anti-utilitariste dans les sciences sociales), seção 'Publications', disponível em <http://www.journaldumauss.net/>.
} 
$\mathrm{Na}$ etnografia, circunscrevi um sistema de emoções musicadas 9 que passei a problematizar como uma categoria da experiência cotidiana, cuja figura tipificadora é a metáfora da morte. Uma das conclusões da dissertação foi a de que se, por um lado, o significante "morte" é atualmente elaborado e vivido sob um interdito - ainda que, ao mesmo tempo, "espetacularizado"-, por outro lado, entre os woodgóticos há uma modalidade de uso do significante "morte" que, relacionalmente, configura-se como antidisciplina (CERTEAU, 2009, p. 87-88) cotidiana, atuando pelas vias de uma micropolítica das emoções, por sua vez, elaborada pelo veículo que denominarei, provisoriamente, por "reflexividade blues punk". Isso porque, a indicada aproximação do caráter simbólico da morte está encarnada nas práticas dos woodgóticos ao longo das várias camadas do cotidiano que, comumente, ablui-se da presença do significante morte.

Conforme indiquei acima, os interlocutores tomam experiências de sofrimento como matéria-prima para seus fazeres musicais, sempre em relação de quiasma com as determinações da desigualdade sobre seus projetos de vida. Interpretei o sofrimento como metáfora da morte localizando, pois, uma categoria da experiência cotidiana como fonte da matéria-prima por eles usada. A seguir, explicitarei a maneira de considerar essa categoria da experiência cotidiana.

\section{METÁFORAS DE MORTE COMO CATEGORIA DE EXPERIÊNCIA COTIDIANA}

Uma ampla bibliografia no campo dos usos do significante morte situa a experiência típica do sofrimento no fato da morte de algo/alguém amado. É típica na medida em que contém em grau extremo e condensado os sentimentos de dor, angústia, aflição, desespero e torpor. Em relação a essa série de sentimentos mortificantes, a experiência do sofrimento na circunstância da morte de algo/alguém amado se apresenta, pois, como o "tipo ideal". Não obstante, através das ambiguidades e contradições da vida cotidiana, todos nós experimentamos circunstâncias outras que

\footnotetext{
${ }^{9}$ Trata-se, neste ponto, de introduzir a conceituação sobre a natureza afetiva da experiência musical a partir de Lévi-Strauss: "Pela música se consuma o prodígio de que o mais intelectual dos sentidos, a audição, normalmente a serviço da linguagem articulada, experimentar um tipo de estado que o filósofo tinha reservado justamente ao olfato, de todos os sentidos o mais profundamente enraizado nos recônditos da vida orgânica. Escapando do entendimento, onde costuma estar sediada, a significação engrena-se diretamente na sensibilidade. Pela música, esta se encontra assim investida de uma função superior e, para o sujeito, inesperada. Daí esse sentimento de gratidão para com a música que o enche de satisfação, sentimento de ter sido repentinamente transformado por ela num ser de essência diferente, no qual princípios normalmente incompatíveis (pelo menos foi isso que lhes ensinaram) se apaziguam e atingem, ao se reconciliarem, uma espécie de unanimidade orgânica. (...) A alegria musical é, então, o da alma convidada, excepcionalmente, a se reconhecer no corpo." (LÉVI-STRAUSS, 2011, p. 633).
} 
contêm essa série de sentimentos, contudo, por graus de intensidade menores em relação ao referido "tipo ideal". Nesse gradual de intensidade, trata-se de reconhecer um gradual de metáforas da morte presentificadas na vida cotidiana, sempre que experimentamos a finitude indesejada de um vínculo. Por esse caminho, o drama da finitude humana ganha presença metafórica mediante a circunstância do fim indesejado de vínculos, em que a intensidade do sofrimento é relativamente simétrica à intensidade do fim indesejado (por exemplo, fim de vínculo com um projeto de vida, fim de vínculo com escolarização, fim de vínculo conjugal, fim de vínculo empregatício, etc.). Por esse caminho, à indicada série de sentimentos mortificantes corresponde uma categoria da experiência cotidiana. Trata-se, portanto, de uma categoria da experiência cotidiana tipificada na metáfora da morte, na medida em que o sofrimento humano tem seu ponto de referência típico na contingência da morte de algo/alguém amado - inclusive de si próprio.

Nesse quadro, o significante morte tende a constituir, em primeiro lugar, o completamente Outro da subjetividade. A construção histórica da formação da noção de indivíduo ocidental se desenvolve homóloga às transformações do significante morte, donde o drama da finitude humana foi transformado, em primeiro lugar, no metadrama da interioridade. ${ }^{10}$ Por consequência, as metáforas da morte ao longo do cotidiano - o sofrimento - atualizam, em primeiro lugar, o fato da precariedade da estadia no mundo reforçando a constituição relacional da subjetividade. Por esse caminho, a categoria da experiência cotidiana delineada acima se deixa interpretar por várias entradas, porém, deter-me-ei aqui no fato de que tal categoria localiza um espaço analítico específico de observação da relação estrutura/ação. Isso porque, nas experiências das metáforas da morte ao longo do cotidiano está, potencialmente, um espaço ontológico da relação estrutura/ação. Passando a um grau de abstração um pouco maior, poderíamos sintetizar a categoria da experiência cotidiana tipificada na metáfora na morte, nomeando-a: negatividade (AGAMBEN, 2006). Com esse gesto seria possível situar o espaço de uma modalidade de conversação interna (ARCHER, 2003, p. 93) nessa categoria da experiência.

Margaret Archer situa a conceituação de "conversações internas" no marco do debate sobre a relação estrutura/agência. 0 trabalho de Archer nessa discussão é considerado, entre outros, por Vandenberghe (2010, p. 258), como a melhor crítica a Giddens; destacando-se na era dos epígonos na teoria sociológica pós-neoclássica (Giddens, Bourdieu, Habermas e Luhmann). A autora desenvolve uma sofisticada teoria morfogenética da emergência, reprodução e transformação dos sistemas culturais e estruturas sociais, sobretudo, apoiando-se no realismo crítico de Roy Bhaskar. Nessa

\footnotetext{
${ }^{10}$ Para apoiar a hipótese sobre a formação da noção de indivíduo em homologia com as transformações do significante morte, Cf. Duby (1978); Le Goff, (2007); Panofsky, (1979, 2001).
} 
chave, as conversações internas consistem no veículo da reflexividade, conforme localizado na citação anterior da mesma autora. Mais propriamente, o conceito nomeia o processo através do qual são mediadas cultura, estrutura social e agência - bem dito, como processo mediador da conexão entre mundo da vida e sistema. Posicionando, desde uma visão estratificada da sociedade, uma medida de ação ao agente resultante do referido processo de mediação (ARCHER, 2003, p. 133). Cabe acrescentar, por fim, que Vandenberghe, em diálogo com Archer, avançou essa discussão "argumentando basicamente que não temos conversações com nós mesmos, mas que somos essas conversações" (2010, p. 323. Grifo do autor).

0 trabalho de campo foi realizado junto a jovens e juvenilidades (PERALVA, 1997; REGULLO, 2003) oriundas de camadas empobrecidas que tomam a mencionada categoria da experiência como lugar da indicada modalidade específica de conversação interna. Por sua vez, transformam essa conversação interna em matéria-prima para um exercício de reflexividade (ARCHER, 2003, p. 167) sobre exclusão, desigualdade e juventude numa linguagem artística, sobretudo, de música pós-punk. Vandenberghe (2010, p.264) observa que Archer faz uma análise, inclusive, sobre as "trilhas sonoras das conversações internas". Interpreto que, para os interlocutores da pesquisa, a indicada modalidade de conversação interna, trasladada à formalidade da linguagem artística por música constitui, em um sentido, uma forma de elaborar uma leitura das regras do espaço social no qual eles se localizam. E, a partir disso, tentam clarear as regras do jogo em relação ao qual necessitam elaborar estratégias de combate, de ação, de resposta às determinações da desigualdade sobre os seus projetos de vida. Isto é, estratégias de combate às determinações da ardilosa desigualdade social em relação ao alto grau de vulnerabilidade de suas prováveis possibilidades no espaço social.

No trabalho de campo observei que as configurações dessa categoria da experiência podem ganhar o caráter simbólico do trágico, presente na relação estrutura/ação do ponto de vista dos interlocutores. Contudo, o processo de reflexividade não para aí. Após passar pela assunção do indicado caráter trágico, então, a partir da mesma sensibilidade, dispõe-se a distinguir possibilidades de exercício para um otimismo da vontade em direção à diminuição da reificação de si.

Para explorar os sentidos dos padrões de mensagem homólogos a padrões de ação alocados no exame do vínculo entre música e reflexividade entre os woodgóticos, por sua vez, direciono a análise para investigar uma modalidade de ação contida na relação entre angústia e ação, portanto, entre ruído e ação na homologia que será evidenciada a seguir a partir de Bateson. Com o intuito de operacionalizar a discussão, delimito que o espaço analítico dentro do qual se desdobrará a presente direção da reflexão é o espaço fractal da proposição de Spinoza $(2002,2007)$, segundo a qual as 
passions tristes estão para a ação em relação de oposição. ${ }^{11}$ Indo e vindo dentro desse espaço analítico, vindo e indo entre os termos dessa oposição, fracionarei em passions tristes uma de suas formas empíricas que é a angústia. Estimo que para fins heurísticos a indicada oposição se deixa problematizar de modo que, ao exercício de propor uma discussão, são colocados problemas que favorecem o seu desenvolvimento. Desenvolverei a seguir uma hipótese de trabalho baseada nestes termos opostos, qual seja, angústia e ação.

Considerando a relação angústia/ação, a presente reflexão é animada pela possibilidade de tomar como hipótese de trabalho uma relação de homologia entre "angústia" (em relação à ação) e "ruído" (em relação à reflexividade). Ao situar "ruído", remete-me ao ensaio A explicação cibernética (2000), no qual Bateson refere que "a questão da localização da informação endemoninhou a teoria da comunicação" e continua, sintetizando: "tudo o que não é informação, nem redundância, nem forma e nem restrição - é ruído, que é a única fonte possível de novos padrões." (BATESON, 2000, p. 416. Grifo do autor. Tradução minha.). Temos, então, padrões de mensagens homólogos a padrões de ação. Com efeito, seria possível considerar a angústia, o ruído do pensamento e da ação, a partir da análise que Lévi-Strauss faz sobre a angústia.

(...) a função simbólica, longe de ser gratificada pela solução imprevista de um problema ao qual estava disposta a se dedicar com afinco, sente-se como que coagida pela necessidade, que as circunstâncias tornam vital, a operar entre campos operatórios ou semânticos, rapidamente, uma síntese cujos meios lhe escapam. E isso tanto para enfrentar a ameaça iminente de uma agressão como para restabelecer o equilibrio de um sistema de vida que 0 desaparecimento de um ente querido, que nele tinha um papel insubstituível, destruiu. Em vez de um trajeto teoricamente laborioso ser evitado pelo atalho do cômico, nesses casos é a incapacidade de conceber um atalho que provoca aquela espécie de paralisia dolorosa, pressionando um espírito aterrorizado diante das dificuldades do trajeto que as vicissitudes da existência lhe impõem e das provações que cada etapa lhe reserva. A fisiologia confirma indiretamente essa interpretação. Com efeito, as neuroses ditas de ansiedade são acompanhadas de uma dose aumentada de derivados do ácido lático no sangue (...) e sabe-se que a produção de ácido lático normalmente resulta do esforço muscular, de que o esforço simbólico exigido até o limite de suas forças, poderia ser o equivalente no âmbito da vida do espírito. Em linguagem de afetividade, a ansiedade seria, assim, a expressão de um estado de obstrução fisiológica que interfere no cálcio que transmite os impulsos nervosos e os paralisa, estado que seria induzido no corpo em razão de uma homologia entre as conjunturas moral e física. Quando essa obstrução resulta de um esforço mecânico demasiado intenso,

${ }^{11}$ Sobre esta oposição entre tassions tristes e ação ver, também, Pelbart (2008). 
traduz-se na linguagem da sensibilidade em câimbras e contrações musculares, de que a angústia, repuxando as vísceras, oferece o equivalente na forma de metáfora encarnada. (LÉVI-STRAUSS, 2011, p 634-635).

Entre as consequências de analisar a angústia nestes termos em relação à atividade simbólica, o autor remete à sugestão de que:

É verdade que são observados nos animais estados talvez comparáveis à angústia, e que a experiência interna nos revela nelas algo de bestial a ponto de nenhuma outra ocorrência ser mais capaz do que a angústia de, aquém da condição humana, nos religar à experiência vivia de nossa natureza animal de origem." ( LÉVI-STRAUSS, 2011, p. 657).

Em seu fim último, tratar-se-ia de emprestar inteligibilidade antropológica à compreensão de uma potencial medida emergente de reflexividade transformadora. Este potencial está presente na relação entre angústia e ação, a partir do modelo explicativo apreendido na obra de Bateson, em relação de mediação com o modo de reflexividade "blues punk" entre os woodgóticos. Tratar-se-ia de uma reflexividade musical, posto que no modo como o padrão que conecta ${ }^{12}$ os termos de sua coerência interna apresenta, por seu lado, isomorfismos entre a formalidade da música, resultado da conversação interna (veículo da reflexividade), e a modalidade de produção de saber (resultado da reflexividade) sobre o tema da negatividade como categoria da experiência cotidiana. Enfim, respostas sobre a experiência de angústia, sobre a relação de quiasma entre a angústia e as determinações das ardilosas contradições das desigualdades sobre seus projetos de vida. Portanto, como diria Niklas Luhmann (2006, p. 490-501), respostas sobre a prontidão oxímora da tragédia da exclusão.

\section{DO INVERSO AO REVERSO: TRANSVERSÕES DO SIGNIFICANTE MORTE, ENTRE AÇÃO E ANGÚSTIA}

Bateson procede por espirais de sínteses cujas curvaturas são mediadas por homologias entre campos operatórios opostos e complementares, oriundos, por um lado, do vivido e, por outro lado, do pensado.

Talvez seja possível interpretar uma medida emergente de transformação potencial na experiência, inclusive, veiculada pela reflexividade musical das metáforas

12 "O padrão que conecta é um metapadrão. Um padrão de padrões. É este metapadrão que define a vasta generalização a qual, aliás, é um padrão que conecta." (BATESON, 1979, p. 11. Grifos do autor. Tradução minha). 
da morte nas obras do II Festival Woodgothic. Assim como Simmel (2005, p. 142), inicialmente podemos sugerir que

É como se fosse necessário que primeiro um pedaço da existência ruísse, para esta se tornar tão sem resistência às correntes e forças que vêm de todas as direções da realidade. Talvez seja esta a sedução da queda, da decadência: ir além de seu mero lado negativo, de seu mero estado rebaixado.

Desde essa perspectiva, a experiência musical pelos woodgóticos talvez guarde em si, inclusive, a produção de presença do bom encontro (SPINOZA, 2002; 2007) ${ }^{13}$, tecnicamente improvável, pois justamente localizado, em um gesto do endemoninhado ruído, nos termos de Bateson, da sensação de estar vivo. Isto é, na medida em que esse processo de reflexividade enleva as passions tristes além de "seu mero lado negativo, de seu mero estado rebaixado" (SIMMEL, 2005, p.142). Isso porque, então, em primeiro lugar, o agente inclui a variável angústia/ruído na integridade da existência ao invés de higienizá-la do cotidiano. Nessa maneira de considerar as passions tristes não somente como parte indecomponível da estadia no mundo, podemos pensá-las, também, como fonte de ruído, isto é, nos termos de Bateson, como fonte de novos padrões de mensagens (o pensado) e de ações (o vivido). Compreenderíamos, então, nas formas musicais, nos imaginários sonoros e nas dinâmicas coletivas que reúnem os woodgóticos, uma direção da realidade com cariz de antidisciplina cotidiana (CERTEAU, 2009, p. 87-88) em relação ao cotidiano arregimentado pela hegemônica normatividade do biopoder. Normatividade esta fundada no insistente interditar das consciências e dos sentidos sobre a questão que a dor traz consigo, em última instância, na interdição da pergunta sobre o sentido da existência. A sensibilidade sobre a medida de reificação de si que vale a pena viver para poder conferir um sentido à vida, à força ontologicamente irredutível a tal normatividade.

Michel Foucault, em Vigiar e Punir, discorrendo sobre a descoberta do corpo como objeto e alvo do poder durante a época clássica, observa que "os famosos autômatos, por seu lado, não eram apenas uma maneira de ilustrar o organismo; eram também bonecos políticos, modelos reduzidos de poder" (1997, p. 118). Nessa perspectiva, partindo da trilha de Foucault, poderíamos, grosso modo, também espreitar precisamente, o modelo reduzido (LÉVI-STRAUSS, 1989, pp. 38-40) dessa invenção moderna, a "interioridade". E então nos aproximamos ao que nos interessa.

Apesar da simplificação arbitrária, sugiro localizar a inversão que Foucault postula em registro analítico como um ponto de partida: "à expiação que tripudia sobre o corpo deve suceder um castigo que atue, profundamente, sobre o coração, o intelecto, a

${ }^{13}$ Sobre "bom encontro" ver, também, Cardoso (2006). 
vontade, as disposições" (1997, p. 18). Faz-se necessário que o leitor me acompanhe nesse raciocínio mantendo sempre no horizonte a relação de homologia colocada na hipótese - homologia entre "angústia" (em relação à ação) e "ruído" (em relação à reflexividade). Pois importa identificar o ruído nessa "interioridade" - desde então morada da reflexividade e tida como fiel depositária da atividade de sintetizar o ruído, referido por Bateson, transformando-o, por homologia, do campo operatório do pensado para o campo operatório da ação.

Sob esse aspecto, Remo Ceserani (2006, p. 98), observa que no século XVIII havia um interesse notável pela descoberta da "vida interior" das crianças e dos adultos. 0 autor assinala que na passagem de século XVIII para o XIX, intensificou-se uma mudança radical nos modelos culturais de sensibilidade na direção de controlar os impulsos e arregimentar - o que é mais importante para nós aqui - uma nova concepção de morte, então, a morte com M maiúscula.

Conforme sintetiza Philippe Ariès, a morte tornou-se o lugar de tomada de consciência do indivíduo: quando essa noção está tomando força, a ideia de individualidade própria a cada homem, ao mesmo tempo, emergem as ostensivas iconografias da morte no século XII. Isto é, uma "ruptura com a familiaridade milenar do homem com a morte" (ARIÈS, 2002, p. 159); "0 homem não pode mais olhar de frente nem o sol nem a morte" (LA ROCHEFOUCAULD apud ARIES, 2002). Por isomorfismo, Ariès (2002, p. 274) afirma que, "a correspondência exata entre o triunfo da morte e o triunfo do indivíduo durante a segunda fase da Idade Média convida-nos a perguntar se não existiria hoje uma relação semelhante, mas inversa, entre a 'crise da morte' e a da individualidade".

Já sobre o autocontrole progressivo, Elias discorreu longamente e, embora não abordemos essa problemática, cumpre, todavia, pontuar o cenário de colocação da questão da angústia que aqui compete. Em $A$ busca da excitação (ELIAS e DUNNING, 1992), o autor apresentou o que Dunning ponderou como um esforço por estabelecer os fundamentos de uma "teoria multidisciplinar das emoções - sociológica, psicológica e fisiológica” (DUNNING, 1992, p. 34). Nesse quadro, Elias conclui que

Nas sociedades avançadas do nosso tempo, muitas profissões, muitas relações privadas e actividades, só proporcionam satisfação se todas as pessoas envolvidas conseguirem manter uma razoável harmonia e um controlo estável dos seus impulsos libidinais, afectivos e emocionais mais espontâneos, assim como os dos seus estados de espírito flutuantes. Nestas sociedades, a sobrevivência e o sucesso dependem, por outras palavras, em certa medida, de uma armadura segura, nem demasiado frágil, nem demasiado forte, de autocontrolo individual. Nas sociedades como esta há um campo de acção muito limitado para a demonstração de sentimentos fortes (...). As pessoas que se agitam demasiado, sob o domínio de 
sentimentos que não podem controlar, são casos para hospital ou para prisões. Determinadas condições de excitação são consideradas anormais em qualquer pessoa e, no caso de multidões, como um perigoso prelúdio de violência. No entanto, a contenção de sentimentos fortes, no sentido de alguém preservar um controlo regular firme e completo dos impulsos, afectos e emoções é um factor de origem de novas tensões. (ELIAS, 1992, p. 69)

É esse o pano de fundo no qual contracenam, por uma parte, ainda na companhia de Elias, a "estrutura de personalidade" e o "código de sensibilidade" (ELIAS, 1992, p. 42-43) que, por outra parte, mediam os usos do significante morte e a experimentação das metáforas da morte. Estes últimos - 0 significante morte e as metáforas da morte-, em termos hegemônicos, sob um regime de interdito, no contexto de um cotidiano condensado pela normatividade do biopoder; que sistematicamente desqualifica a morte produzindo a retirada de seu estatuto de existência, uma vez que "a velha potência da morte em que se simbolizava o poder soberano é agora, cuidadosamente, recoberta pela administração dos corpos e pela gestão calculista da vida" (FOUCAULT, 2009, p. 131). Portanto, "pode-se dizer que o velho direito de causar a morte ou deixar viver foi substituído por um poder de causar a vida ou devolver à morte." (2009, p. 130).

Pelbart resume com destreza uma das faces desse espaço do biopoder, da relação entre poder e vida:

(...) o poder tomou de assalto a vida. Isso é, o poder penetrou todas as esferas da existência, e as mobilizou inteiramente, e as pôs para trabalhar. Desde os genes, o corpo, a afetividade, o psiquismo, até a inteligência, a imaginação, a criatividade, tudo isso foi violado, invadido, colonizado, quando não diretamente expropriado pelos poderes. Mas o que são os poderes? Digamos, para ir rápido, com todos os riscos de simplificação: as ciências, o Estado, a mídia. Os mecanismos diversos pelos quais eles se exercem são anônimos, esparramados, flexíveis, rizomáticos. (...) Com isso, ele incide sobre nossas maneiras de perceber, de sentir, de amar, de pensar, até mesmo de criar. Se antes ainda imaginávamos ter espaços preservados da ingerência direta dos poderes (o corpo, o inconsciente, a subjetividade), e tínhamos a ilusão de preservar em relação a eles alguma autonomia, hoje, nossa vida parece integralmente subsumida a tais mecanismos de modulação da existência. Até mesmo o sexo, a linguagem, a comunicação, a vida onírica, mesmo a fé, nada disso preserva já qualquer exterioridade em relação aos mecanismos de monitoramente e controle. (...) Não estamos mais às voltas com um poder transcendente, ou mesmo repressivo; trata-se de um poder imanente, produtivo. Esse biopoder não visa barrar a vida, mas encarregar-se dela, 
intensificá-la, otimizá-la. (...) Nunca o poder chegou tão longe e tão fundo no cerne da subjetividade e da própria vida como nessa modalidade de biopoder. É onde intervém o segundo eixo que seria preciso evocar, sobretudo em autores provenientes da autonomia italiana. (...) quando parece que "está tudo dominado", como diz um rap brasileiro, no extremo da linha se insinua uma reviravolta: aquilo que parecia submetido, controlado, dominado, isto é, "a vida", revela no processo mesmo de expropriação, sua potência indomável. (PELBART, 2009, p. 25-26).

Nesse quadro, faz-se necessário situar o espaço em relação ao qual adquire forma uma micropolítica das emoções, dimanada no processo de tomar como espaço de conversação interna e trasladar à linguagem musical uma categoria da experiência cotidiana, sistematicamente exilada pela normatividade hegemônica do biopoder. Isto é, situar o padrão de sensibilidade e a estrutura de personalidade deuteroaprendidos na direção de dirimir o estatuto de existência da categoria da experiência, a partir da produção de uma máquina de fazer desaparecer a morte e de bestializar o sofrimento (em um sentido, pois, o ruído em relação à ação). Ao fim e ao cabo, trata-se de um regime especular de pornografia da dor, de obscenidade da angústia, das metáforas da morte, de reificação da "vida" na linguagem da biomedicina hegemônica; isto é, na linguagem predominante de emissão de mensagens tidas legítimas sobre o significante morte.

Conforme Philippe Ariès (2003) e Michel Vovelle (1996), a partir da década de 1930, instaurou-se nas sociedades ocidentais um interdito sobre a morte. Isto é, começou a predominar a tendência de negar e marginalizar o fato da morte no contexto do cotidiano, o fato do drama da finitude humana no contexto da integridade da existência. José Carlos Rodrigues, após analisar a construção histórica do tema da morte no ocidente, conclui que

A regra em nossa sociedade é a neutralização dos ritos funerários e a ocultação de tudo que diga respeito à morte. (...) por que nossa civilização nega a morte, não pode suportar sua ritualização; $\mathrm{e}$, inversamente, por não possuir os necessários instrumentos rituais para enfrentá-la, a civilização ocidental moderna é obrigada a banir a morte e a negá-la por todos os meios. (RODRIGUES, 2006, p. 165)

Tal negação implica a transformação da morte em um dado técnico localizado, via de regra, sob o poder biomédico. Por conseguinte, "a medicalização penetra fundo em nossas vidas e constitui um dos domínios em que o poder da técnica foi mais bem acolhido e menos contestado" (RODRIGUES, 2006, p. 194). Em última instância, a condição humana se torna signatária à medicalização da vida biológica e psíquica. Por 
consequência, em suma, se todas as culturas humanas elaboram uma resposta para 0 drama ruidoso da finitude humana, a resposta de nossa cultura ocidental hegemônica atual, oriunda da linguagem biomédica, por sua vez, pulsa na retirada do estatuto de existência da morte, no silenciamento progressivo da dor psíquica, em última análise, na ablução sequencial do cotidiano em relação às metáforas da morte. 0 que possui muitas metaconsequências perigosas, tornando-se um paradoxo insustentável. Primeva contradição em termos. Se um oposto cria e sustenta o sentido do outro, então, simular que não existe morte significa não somente assinar um atestado de capilaridade da vida nua (ação nua) (AGAMBEN, 2010), uma vez que posiciona a vibratibilidade da ação humana fora da sua própria razão antropológica ${ }^{14}$, mas, por contiguidade, desloca-a para o lugar do animal, da máquina, das coisas (que não morrem, mas cessam de viver).

Neste percurso, haveríamos de concordar com a filosofia indígena analisada por Lévi-Strauss sobre ritos funerários dos fox: "a morte é dura; mais dura ainda é a tristeza" (LÉVI-STRAUSS, 1989, p. 47). A passagem permite ressaltar que mais dura ainda é a tristeza no cotidiano arregimento pela normatividade hegemônica do biopoder na medida em que, nesse contexto, são deformadas a reificação da ética e a ininteligibilidade da economia da distribuição desigual do poder de ação. Ou seja, a passagem ressalta a produção social da alegria tanto quanto a de seu oposto, a tristeza, permitindo, então, colocar relevo sobre os regulamentos tanatopolíticos (AGAMBEN, 2010, p. 160) operatórios nas consequências antropológicas desse regime de emoções, já agora, tornadas não só experiência envergonhada como, sobremaneira, obscena. No mesmo passo, em relação à referida normatividade hegemônica, resulta a necessidade de politizar as emoções, particularmente, as metáforas da morte - o sofrer.

\section{CONSIDERAÇÕES FINAIS - PASSOS PARA UMA TEORIA DA AÇÃO DESDE BATESON}

Por este caminho, a expressão "ruído em estribilho", que poderia estar contida no título deste texto, faz referência às metáforas da morte - 0 sofrimento - na posição de estribilho nos fazeres musicais dos woodgóticos. Nessa formulação, "ruído" tenciona exprimir, simultaneamente, por uma parte, a presença e o uso específico por parte dos

\footnotetext{
${ }^{14}$ Entendo por "razão antropológica" uma sistemática de categorias autorreferentes entre si predicadas à condição humana: posse de consciência, de volição, de intenção, de ideias, de desejos, de vontades; a partir da relação de disjunção entre humanos e inumanos (animais, máquinas ou coisas) e, por contiguidade, são termos aplicados à ontologia do vocábulo "ação". Ao falar sobre "razão antropológica" impõe-se pensar "razão antropológica ocidental", precisamente, na medida em que a Antropologia ou a antropologia são produtos do sistema de classificação da tradição ocidental. Por "razão" entendo a sistemática de categorias que numa progressão opera sempre do mesmo modo.
} 
woodgóticos do ruído em suas músicas - entendido como o código sonoro externo à organização de sons figurativos inteligíveis pelas categorias de pensamento do ouvinte e, por outra parte, tenciona exprimir a indicação dessa modalidade de metáfora da morte, precisamente, como ruído do pensamento e da ação, conforme discorrido acima. Portanto, a partir da formulação de ruído por Bateson como códigos de comunicação em homologia a padrões de ação, interpreto a angústia recorrente no imaginário sonoro das metáforas da morte como ruído do pensamento e da ação alinhado à elaboração de "novos padrões", padrões de mensagens e de ações. Neste caso, direcionados em relação às respostas, às determinações da desigualdade sobre os projetos de vida do agente. Por outras palavras, a reflexividade blues punk guardaria em si uma medida de potencial transformativo ao passo do fazer emergir uma leitura das regras do espaço social, a partir da qual o agente inscreve percursos de vida tecnicamente improváveis em relação às regras de reprodução do espaço social (BOURDIEU, 2011, p. 63).

Uma ideia recorrente nos relatos sobre o II Festival Woodgothic é a de que "a cena pós-punk estava lá". "Cena pós-punk" é a expressão verbal pela qual os góticos designam a si em coletivo. Não obstante, importa concentrar a atenção no fato de que mais do que uma soma de pós-punks, o plural designado por "cena" tem por premissa a atividade, a ação, o uso, a invenção do cotidiano. Mais do que um conjunto de indivíduos, "cena" é um vocábulo usado para evocar a formalidade e a modalidade de uma província de lazer com cariz de transgressão que constrói engenharias para o lazer por fazeres artísticos.

Nesse quadro, sugiro que para além do negrume sonoro e visual (um pensamento que ganha decodificação pela comunicação de uma composição sensível exposta a outrem no próprio corpo de si) está o desejo de uso-fruir a diversão oferecida por essa atividade festiva (o II Festival Woodgothic) dessa província de inflexão (cena pós-punk) A articulação entre atividade festiva/inflexão e diversão é ocasionada pela afetação entre arte e experiência, conduzida pela reflexividade musical e mediada pelas conversações internas de cada agente. Dessa forma, desde a ideia de "cena pós-punk" acessamos o fato de que simultâneo ao negrume visual e sonoro e à diversão festiva está o princípio de transversão que a funda.

A noção de transversão utilizada neste trabalho surge da experiência etnográfica e das interpretações de conceitos nativos. Por um lado, da experiência etnográfica de conversar e entrevistar (com auxílio de gravador) os woodgóticos andando pelas ruas de São Thomé das Letras, tomadas por uma densa neblina que não permitia algo ver nitidamente a mais de três metros. Tal paisagem impeliu-me à ideia de "trans-ver". Trans no sentido de "transsex", "transgênero", "transgênico", "transversal": isto é, uma definição que atravessa duas ou mais categorias e não se apega a alguma, portanto, em busca de especificidade e legitimidade em relação a categorias previamente mais 
distinguíveis. Nessa direção, quando refiro que os woodgóticos eram "transvistos" nas ruas de São Thomé das Letras estou, portanto, indicando um modo de se dar a ver mediado pelas propriedades da neblina; tais como o aspecto embaçado, as imagens desmanchando-se no ar, a qualidade etérea da solidez do próprio corpo.

Por outro lado, a esse modo trans-de-visão, aproximei alguns conceitos nativos. Isso porque, pareceu-me que "trans", na acepção indicada acima, pode ser direcionado para um uso em outro registro analítico, qual seja: o nomeador do modo de funcionamento das metáforas da morte no woodgothic: trans-versões do significante morte. Trata-se de um uso de "trans", todavia, associado à ideia de "versão". Por esse caminho, a versão de representação da morte hegemônica (oriunda da linguagem da biomedicina) está suposta no fato de que existe uma gama de variadas outras versões de representações da morte, conforme os diferentes espaços sociais ao longo do cotidiano. Assim, então, a noção de transversão aproxima-se à de "transgressão", porém, mantém sua distância e especificidade. 0 tom fluido de uma versão ganha em plasticidade relativamente à postura algo mais definitiva de "transgressão" ou mesmo de "subversão". É justamente na razão da indicada plasticidade que havia necessidade de alcançar uma ferramenta analítica, pois é o elemento que especifica o modo de funcionamento das metáforas da morte no Woodgothic. Isso porque, mais do que se preocupar com a manutenção de uma posição de "transgressão", trata-se, para os interlocutores, em primeiro lugar, de produzir versões que portem a mensagem de que outras formas de usos do significante morte e suas mensagens são possíveis em relação à hegemônica. Por sua vez, o fato de a produção das mencionadas versões do significante morte caracterizarem ou não transgressão coloca-se, pois, em posição secundária: uma consequência cuja ocorrência não é a regra.

0 modo transversivo de funcionamento das metáforas da morte no Woodgothic configura-se, por homologia, pelas componentes mesmas do modo trans-de-visão dos woodgóticos durantes os dias do festival em meio à neblina: 0 aspecto embaçado das mensagens às vezes dificilmente codificadas, as imagens desmanchando-se no ar, a qualidade etérea amalgamada à solidez.

Trata-se, então, de tentar apreender a razão plástica que se movimenta entre duas posições polarizadas: 1) a definição hegemônica de representação da morte e 2) a definição, talvez mais insustentável, de oposição radical à definição hegemônica. Assim, então, transitando entre tais polos opostos estaria a versão trans operacionalizada nas metáforas da morte presentes nos fazeres artísticos woodgóticos. Portanto, o uso da noção de transversão tem por objetivo tentar apreender a razão plástica, sua pulsação e movimento tentativo, identificada na etnografia da modalidade de representação da morte presente nos fazeres artísticos do II Festival Woodgothic, que é uma partícula condensada da cena pós-punk e de suas demais transversões. 
Nesse quadro, por fim, para os woodgóticos, torna-se premente experimentar um candente fraseado em tonalidades blues punk que pulsa por gestos visualizáveis na inscrição corporal de si. Recolhida sobre si, manifesta como corpo do Eu, celebrada na algaravia do Festival, a reflexividade blues punk se manifesta para os woodgóticos em toda sua - agora deles - potência transversiva: a reflexividade blues punk, em última análise, é "um tipo de modus vivendi que um agente procura estabelecer no mundo" (ARCHER, 2003, p. 167). Portanto, é não apenas um ponto de ver e deliberar ações (o que não é pouco), mas procede por estender-se como plataforma existencial, já então, é a sua própria vida enquanto não só a si pertence.

Por fim, almejo ter ilustrado que alguns conceitos de Bateson demonstram de forma emblemática a ligação entre o tema da reflexividade, do funcionamento da ação sob o signo da relacionalidade e, em última instância, a convergência de ambos os temas em direção à questão da medida de transformação social em relação à diminuição da desigualdade e da reificação de si. Nessa trilha, mantenho no horizonte uma maneira de considerar essa questão pela perspectiva inspirada por Vandenberghe:

Se uma sociologia crítica pressupõe não apenas uma análise das forças da dominação social, mas também uma análise das forças sociais de emancipação, bem como a possibilidade de uma política transformativa emancipatória, então, ela também pressupõe uma ética, ou, ao menos, alguma formulação de critérios normativos de julgamentos morais e alguma indicação da 'boa vida'. (VANDENBERGHE, 2010, p. 84)

Ao considerar as contribuições da obra de Bateson para uma teoria da ação, sugiro que a sistemática da coerência interna ao pensamento deste autor pode ser lida como uma filosofia sobre a relação ordem/ação. Por outro lado, procuro a sociologia contida nessa filosofia e sugiro que é uma sociologia da mudança social em seus desdobramentos axiológicos e políticos sobre a economia da distribuição desigual do poder de ação, a partir do enfoque nos mecanismos de funcionamento da ação sob o signo da relacionalidade (em modo emblemático no conceito de "contexto" sintetizado como a razão sinal/ruído (BATESON, 2000, p. 419)). Nesse enfoque, identifico uma fonte relevante das contribuições desse autor para pensarmos ferramentas conceituais de entendimento das conversações internas articuladas a uma medida de transformação. Bateson nos ajuda a olhar como as dobradiças da experiência guardam em si potencialidades de mudança tanto moleculares quanto granulares, pois a formalidade própria da experiência estrutura-se por uma reflexividade plástica. 


\section{REFERÊNCIAS}

ABRAMO, Helena. Cenas Juvenis - punks e darks no cenário urbano. São Paulo: Editora Página Aberta, 1994.

AGAMBEN, Giorgio. A linguagem e a morte - um seminário sobre o lugar da negatividade. Belo Horizonte: Editora da UFMG, [1985] 2006.

AGAMBEN, Giorgio. Lo abierto - el hombre y el animal. Buenos Aires: Adriana Hidalgo Editora, [2002] 2007.

AGAMBEN, Giorgio. Homo sacer - o poder soberano e a vida nua I. Belo Horizonte: Editora UFMG, [1995] 2010.

ARCHER, Margaret. Structure, agency and the internal conversation. Cambridge: Cambridge University Press, 2003.

ARIÈS, Philippe. História da morte no Ocidente. Da Idade Média aos nossos dias. São Paulo: Ediouro, 2002.

BATESON, Gregory. Steps to an ecology of mind. Chicago and London: University of Chicago Press, [1972] 2000.

BATESON, Gregory. Mente e natureza - a unidade necessária. Rio de Janeiro: Francisco Alves, [1979] 1986.

BATESON, Gregory e BATESON, Mary. El temor de los ángeles - epistemología de lo sagrado. Barcelona: Gedisa, [1987] 1994.

BILIATTTO, Carusa. A morte e seu duplo - micropolítica das emoções no II Festival Woodgothic. Dissertação em Antropologia Social. Universidade Federal de Paraná, Curitiba, 2012.

BOURDIEU, Pierre. Razões práticas - sobre a teoria da ação. Campinas: Papirus, [1994] 2011.

CARDOSO, Hélio. Espinosa e Nietzsche - elos onto-práticos para uma ética da imanência. In: Anais do I Seminário de Filosofia Contemporânea: Nietzsche e o pensamento francês. Londrina: UEL, 2006.

CESERANI, Remo. O fantástico. Londrina: EDUEL; Curitiba: EDUFPR, 2006.

CERTEAU, Michel de. A invenção do cotidiano. Vol. 1 As artes de fazer. Petrópolis: Vozes, [1980] 2009.

DUBY, Georges. O tempo das catedrais. Lisboa: Estampa, [1967] 1978.

DUNNING, Eric. Prefácio. In: ELIAS, Norbert e DUNNING, Eric. A busca da excitação. Lisboa: Difel, [1985] 1992. 
ELIAS, Norbert. Introdução. In: ELIAS, Norbert e DUNNING, Eric. A busca da excitação. Lisboa: Difel, [1985] 1992.

FEIXA, Carles. El Reloj de Arena - Culturas Juveniles en México. México: D. R. Causa Jovem/Centro de Investigación y Estúdios sobre Juventud, 1998. (Colección jóvenes, N.4).

FERREIRA, Victor. Ondas, cenas e microculturas juvenis. Plural, Revista do Programa de Pós-Graduação em Sociologia da USP. v.15, p. 99-128, 2008.

FERREIRA, Victor. Cenas Juvenis, Políticas de Resistência e Artes de Existência. Trajectos, n. 12. p. 111-120, 2010.

FOUCAULT, Michel. Vigiar e punir - o nascimento da prisão. Petrópolis: Vozes, [1975] 1997.

FOUCAULT, Michel. História da sexualidade. A vontade de saber. Rio de Janeiro: Graal, [1976] 2009.

FRANCO JÚNIOR, Hilário. A Idade Média, o nascimento do Ocidente. São Paulo: Brasiliense, 2006.

FREIRE FILHO, João. Reinvenções da resistência juvenil - os estudos culturais e as micropolíticas do cotidiano. Rio de Janeiro: Mauad X, 2007.

LE GOFF, Jacques. As raízes medievais da Europa. Petrópolis: Vozes, [2003] 2007.

LÉVI-STRAUSS, Claude. O bomem nu. (Mitológicas v.4). São Paulo: CosacNaify, [1971] 2011.

LÉVI-STRAUSS, Claude. O pensamento selvagem. São Paulo: Papirus, [1962] 1989.

LUHMANN, Niklas. La sociedad de la sociedad. Ciudad de México: Herder; Universidad Iberoamericana, [1997] 2006.

MANIFESTO CONVIVIALISTA. Declaração de interdependência. São Paulo: Annablume, 2013.

PAIS, José. Machado. Ganchos, tachos e biscates - jovens trabalho e futuro. Porto: Ambar, 2001.

PANOFSKY, Ervin. O significado nas artes visuais. São Paulo: Martins Fontes, [1955] 1979 .

PANOFSKY, Ervin. Arquitetura gótica e escolástica. São Paulo: Martins Fontes, [1967] 2001.

PELBART, Peter Pal. Elementos para uma cartografia da grupalidade. In: SAADI, Fátima e GARCIA, Silvana. (Orgs.). Próximo Ato - questões da teatralidade contemporânea. São Paulo: Itaú Cultural, 2008. 
PELBART, Peter Pal. Por um corpo vivo: cartografias biopolíticas. In: LOBOSQUE, A. (org.) Anais do Seminário Universidade e Reforma Psiquiátrica - interrogando a distância. Belo Horizonte: ESP-MG. Vol. 2, 2009.

PERALVA, Angelina. 0 jovem como modelo cultural. Revista Brasileira de Educação. n. 6. p. $15-24,1997$.

REGUILLO, Rossana. Las culturas juveniles: un campo de estudio; breve agenda para la discusión. Revista Brasileira de Educação. n. 23, p. 103-118, 2003.

RODRIGUES, José Carlos. Tabu da morte. Rio de Janeiro: FIOCRUZ, 2006.

SIMMEL, Georg. A ruína. In SOUZA, Jessé e ÖELZE, Berthold (Orgs.) Simmel e a modernidade. Brasília: Editora da UnB, 2005

SIMMEL, Georg. Sobre la aventura. Barcelona: Ediciones Península, 1998.

SPINOZA, Benedictus de. Complete works. Indianapolis and Cambridge: Hackett Publishing, 2002.

SPINOZA, Benedictus de. Ética. Belo Horizonte: Autêntica, 2007.

TURNER, Victor. O processo ritual - estrutura e antiestrutura. Petrópolis: Vozes, 1974.

VANDENBERGHE, Frédéric. Teoria social realista - um diálogo franco-britânico. Belo Horizonte: Editora UFMG; Rio de Janeiro: IUPERJ, 2010.

VOVELLE, Michel. A história dos homens no espelho da morte. In BRAET, H. e VERBEKE, W. (Eds.) A morte na Idade Média. São Paulo: EDUSP, 1996. 